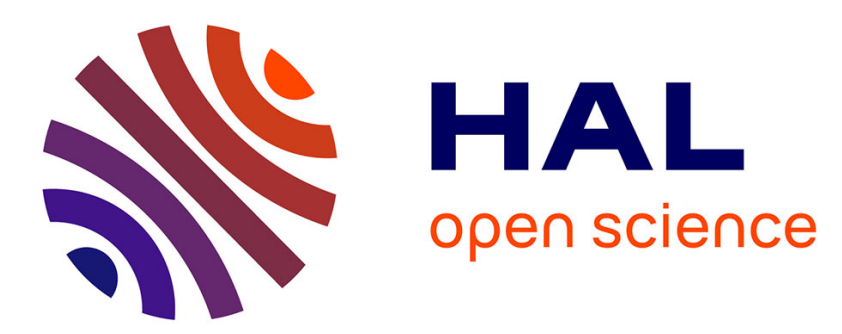

\title{
Reaction of calcium phosphate with textile dyes for purification of wastewaters
}

W. Lemlikchi, P. Sharrock, M. O. O Mecherri, M. Fiallo, Ange Nzihou

\section{To cite this version:}

W. Lemlikchi, P. Sharrock, M. O. O Mecherri, M. Fiallo, Ange Nzihou. Reaction of calcium phosphate with textile dyes for purification of wastewaters. Desalination and Water Treatment, 2014, 52 (7-9), p.1669-1673. 10.1080/19443994.2013.807008 . hal-01625028

\section{HAL Id: hal-01625028 \\ https://hal.science/hal-01625028}

Submitted on 31 Jan 2019

HAL is a multi-disciplinary open access archive for the deposit and dissemination of scientific research documents, whether they are published or not. The documents may come from teaching and research institutions in France or abroad, or from public or private research centers.
L'archive ouverte pluridisciplinaire HAL, est destinée au dépôt et à la diffusion de documents scientifiques de niveau recherche, publiés ou non, émanant des établissements d'enseignement et de recherche français ou étrangers, des laboratoires publics ou privés. 


\title{
Reaction of calcium phosphate with textile dyes for purification of wastewaters
}

\author{
W. Lemlikchi ${ }^{a}$, P. Sharrock ${ }^{\mathrm{b}, *}$, M.O. Mecherri ${ }^{\mathrm{a}}$, M. Fiallo ${ }^{\mathrm{b}}$, A. Nzihou $^{\mathrm{c}}$ \\ ${ }^{a}$ Université Mouloud Mammeri Laboratoire LCAGC, Tizi-Ouzou 15000, Algeria \\ ${ }^{b}$ Laboratoire SIMAD, Université Paul Sabatier, Toulouse 31062, France \\ Email: patrick.sharrock@iut-tlse3.fr \\ ${ }^{c}$ Rapsodee, CNRS 5302, Univeristé de Toulouse, Mines-Albi, Albi 81000, France
}

\begin{abstract}
When unsintered hydroxyapatite (HA) is dissolved in acidic solution ( $\mathrm{pH}$ less than 3), the calcium salt dissolves readily and may be re-precipitated at neutral $\mathrm{pH}$ values by neutralization with base. Maturation of this precipitate eventually leads to the neo-formation of calcium phosphates similar to HA. HA is a stable solid under neutral or basic conditions and has interesting adsorption properties. Particularly, textile dyes can be adsorbed on HA particles. Thermal treatment below $800^{\circ} \mathrm{C}$ degrades adsorbed organic matter and generates mineral HA. Such HA can be recovered and reused by re-dissolution in acidic water. We have experimented with such recycled HA the co-precipitation of textile dyes and found that HA can be reused several times. For most textile dyes, a very high level of color removal was observed (above $98 \%$ ), with a small loss of HA during the recycling process (12\%). This makes the treatment of textile dye polluted waters by HA co-precipitation feasible and sustainable.
\end{abstract}

Keywords: Dye removal; Hydroxyapatite; Adsorbent regeneration; Elimination rate

\section{Introduction}

One of the more challenging problems with industrial waters polluted with textile dyes is finding an economical treatment prior to environmental discharge, avoiding the formation of large amounts of wastes following the treatment process. Indeed, whether the treatment method uses chemical, biological, or electrical means, large amounts of sludge result which are difficult to handle and eliminate [1]. It is of current interest to develop sustainable dye removal

*Corresponding author. processes which do not simply result in waste displacement from liquid to solid phases which prove difficult to manage. Adsorption is a simple purification technique that is often applied with inexpensive adsorbents in order to clarify wastewaters [2]. Thereafter, organic solids can sometimes be composted or burned [3-8]. It is difficult to regenerate activated carbon by thermal treatments, but carbon compounds can be incinerated. Mineral adsorbents are usually disposed of in landfills [9]. The aim of this research was to evaluate the possibility of using hydroxyapatite (HA) calcium phosphates as an economical reagent to purify textile dye 
wastewaters [10,11] and investigate the valorization of the mineral phase of the waste following a thermal treatment to regenerate the HA mineral residue. Another motivation lies in the fact that water treatment with HA precipitation occurs near neutral $\mathrm{pH}$ values, thus allowing the treated water to be returned to the environment without having to adjust the effluent $\mathrm{pH}$. In addition, HA is not an environmentally dangerous product and is commonly found in soils as phosphate rock [12].

Previous work on dye removal by adsorption has been reviewed [13] and activated carbon compared to bone char, chitin, and chitosan products. Cross-linked chitosan beads appeared to have much large capacities than carbon. Solid HA is known to adsorb about $30 \mathrm{mg} / \mathrm{g}$ of calcium phosphate [14,15]. Although some authors reported no adsorption for reactive yellow dyes and only a weak adsorption (below $8 \mathrm{mg}$ of dye/g of calcium phosphate) for other reactive dyes. We noticed that solid HA powders became coated with red color when exposed to Congo red, but that the amount adsorbed was negligible. However, large measurable amounts were removed from aqueous solutions when the HA was precipitated in situ. This indicates the primordial importance of surface effects, but may be interpreted as complexing behavior, as claimed for calcium-rich fly ash [16]. To elucidate this question, we carried out experiments on co-precipitation of HA in the presence of the organic dyes.

\section{Experimental}

The textile dye characteristics are presented in Table 1. Synthetic dye solutions were made by dissolution in distilled water at a concentration of $50 \mathrm{mg} / \mathrm{L}$. HA solutions were made by adding drops

Table 1

Characteristics of the dyes used

\begin{tabular}{|c|c|c|c|}
\hline Abbreviations & $\begin{array}{l}\text { Commercial } \\
\text { name }\end{array}$ & C.I. name & $\begin{array}{l}\lambda_{\max } \\
(\mathrm{nm})\end{array}$ \\
\hline DR & $\begin{array}{l}\text { Dianix Red } \\
\text { HBSL }\end{array}$ & $\begin{array}{l}\text { Red } \\
\text { Disperse } \\
167\end{array}$ & 460 \\
\hline $\mathrm{AR}$ & Alizarine Red S & $\begin{array}{l}\text { Mordant } \\
\text { Red } 3\end{array}$ & $\begin{array}{l}420 \\
(\mathrm{pH}=2)\end{array}$ \\
\hline $\mathrm{HB}$ & Hydron Blue R & Vat Blue 43 & 600 \\
\hline ТВ & $\begin{array}{l}\text { Turquoise Blue } \\
\text { PGR }\end{array}$ & $\begin{array}{l}\text { Reactive } \\
\text { Blue } 72\end{array}$ & 662 \\
\hline ST & $\begin{array}{l}\text { Solophenyl } \\
\text { Turquoise BRLE }\end{array}$ & $\begin{array}{l}\text { Direct Blue } \\
199\end{array}$ & 605 \\
\hline $\mathrm{CB}$ & $\begin{array}{l}\text { Cibacron } \\
\text { Blue P3R }\end{array}$ & $\begin{array}{l}\text { Reactive } \\
\text { Blue } 49\end{array}$ & 587 \\
\hline
\end{tabular}

of concentrated $\mathrm{HCl}$ to a stirred suspension of $100 \mathrm{mg}$ of synthetic HA powder in $100 \mathrm{~mL}$ of distilled water until the $\mathrm{pH}$ value reached 2 , and all solids were dissolved. The first batch of HA was prepared by mixing $\mathrm{CaCl}_{2}$ and $\mathrm{K}_{3} \mathrm{PO}_{4}$ in water in stoichiometric molar ratios of 1.7 .

Batch treatments were carried out at room temperature in air by mixing $100 \mathrm{ml}$ of synthetic dye solutions with the chosen amount of HA solution, re-adjusting the $\mathrm{pH}$ value to 8 , and stirring for $5 \mathrm{~min}$ at $120 \mathrm{rpm}$ followed by decantation during $15 \mathrm{~min}$ or $6 \mathrm{~h}$. The solids were recovered from the decanted suspensions by filtration at atmospheric pressure on Whatman filter papers, followed by drying at room temperature overnight. The collected solids were then heated to $800^{\circ} \mathrm{C}$ for a $10 \mathrm{~min}$ period inside a tubular 21,100 Thermolyne furnace in open air crucibles, at the maximum heating rate $(30 \mathrm{~min}$ from room to max temperature). The cooled solids were recovered and weighed on a Sartorius balance to a precision of $0.1 \mathrm{mg}$. Thermal analyses were carried out with a TGA/DSC apparatus, SDT Q600 by TA Instruments. Samples near $15 \mathrm{mg}$ of the solid were heated over the temperature range from ambient to $1,000^{\circ} \mathrm{C}$ at a heating rate of $5^{\circ} \mathrm{C} / \mathrm{min}$. in air atmosphere with a $100 \mathrm{~mL} \mathrm{~min}^{-1}$ flow rate. Samples were analyzed in platinum crucibles, and the reference was an empty platinum pan. Thermo-mechanical analysis (TMA) was carried out in a Setaram Setsys $16 / 18$ with $5 \mathrm{~g}$ of constant load on the powder sample under air atmosphere with the heating rate of $10^{\circ} \mathrm{C} \mathrm{min}^{-1}$. X-ray diffraction (XRD) measurements were carried out using a Phillips Panalytical X'pert Pro MPD diffractometer with a Cu Ka (1.543 $\AA$ ) radiation source. Infrared spectra were recorded with a Mattson Genesis II spectrometer in the ATR mode using a diamond anvil from Specac.

Repeat experiments were made with the recovered HA solids re-dissolved in dilute $\mathrm{HCl}$ and contacted with the same amounts of dye solutions to obtain identical dye/adsorbent ratios. This was carried out on 5 consecutive runs, and the dye removal was measured at each step as well as the \% recovery of HA after heat treatment. Further trials were conducted by keeping the same amount of dyes and reusing the recovered HA in decreasing amounts. The dye to adsorbent ratios then increased progressively. In each case, the dye removal efficiencies were measured by UV-Vis spectroscopy of filtered solutions using a Perkin-Elmer Lambda2 spectrometer with $1 \mathrm{~cm}$ path length quartz cells and correcting for dilution when necessary.

In the case of the large HA/dye ratio tested, the constant mass ratio used was 20 and the decantation 
times were $15 \mathrm{~min}$. Two dyes were used (HB and DR) and the results expressed as average value (with calculated standard deviation).

\section{Results and discussion}

When the $\mathrm{pH}$ of dye containing solutions was adjusted to $\mathrm{pH} 8$, and in the presence of calcium and phosphate ions, a precipitate formed rapidly which decolorized the solutions. This eliminates the toxic dyes [17]. Following filtration, the remaining absorbance allowed to calculate the amount of dye removal. Normally, pure HA is a white solid, but in the presence of dyes, the HA precipitates were colored. Thermal analysis revealed that a weight loss between 14 and $15 \%$ of the dried weight occurred between 120 and $180^{\circ} \mathrm{C}$, attributed to water loss. The next heating step to $800^{\circ} \mathrm{C}$ caused a weight loss between 30 and $33 \%$ of the initial dry mass and was attributed to organic matter combustion. As illustrated in Fig. 1, the differential scanning calorimetric curves showed the first mass loss was endothermic, confirming the evaporation of water, while the second weight loss was exothermic, confirming the combustion of organic matter above $300^{\circ} \mathrm{C}$.

The TMA curves illustrated in Fig. 2 show that HA sintering occurs above $800^{\circ} \mathrm{C}$ for $\mathrm{HA}$ and that freshly prepared HA shows an additional contraction near $100^{\circ} \mathrm{C}$ corresponding to water evaporation and accompanying shrinkage during drying. On the other hand, the regenerated calcium phosphate following combustion of the dyes showed some thermal expansion below $800^{\circ} \mathrm{C}$, followed by contraction due to sintering above $800^{\circ} \mathrm{C}$. No weight losses occurred for

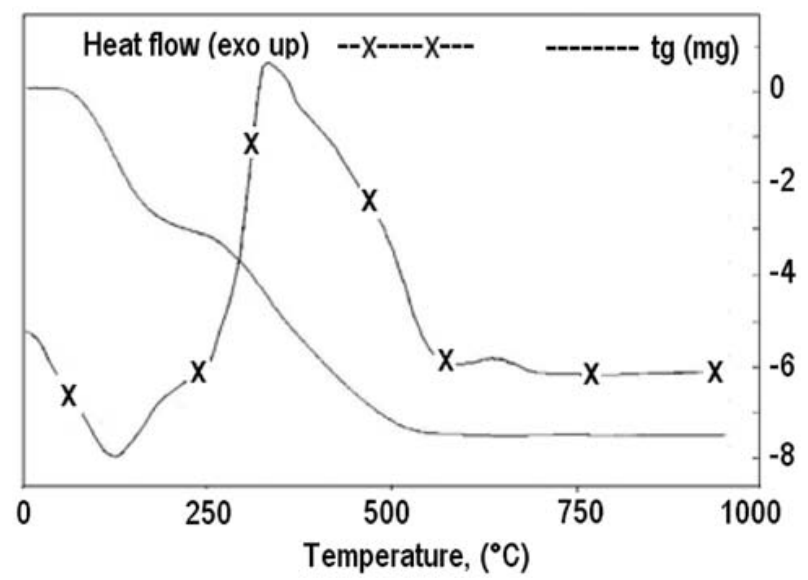

Fig. 1. Thermogravimetric curve of dye adsorbed on HA after 4th calcination. The heat flow curve is marked with $\mathrm{X}$. the same product in the same temperature range corresponding to expansion and sintering. Infrared spectroscopy confirmed the presence of new peaks attributed to organic dyes in the spectra of the co-precipitated products. The strong phosphate absorption band at $1,002 \mathrm{~cm}^{-1}$ dominated the spectra (see Fig. 3).

An excess of HA with respect to the dye concentration (mass of HA precipitated $>$ mass of dye in solution) resulted in a better clarification of the water. Following the thermal treatment, the recovered HA consisted in a white powder with an infrared spectrum typical of HA. XRD showed that the freshly precipitated solid consisted in poorly crystallized HA, whereas the calcined solid corresponded to better crystallized HA, as illustrated in Fig. 4. Because at the calcination temperature below $800^{\circ} \mathrm{C}$ HA was not sintered, it could be easily dissolved in dilute $\mathrm{HCl}$, for reuse in another co-precipitation stage with another batch of dyed water.

On the average, about $85 \%$ of spent reagent was recovered as calcined HA in the case of textile dyes, while $78 \%$ was recovered for Alizarin AR after the first calcination. After the second calcination, the recovery yields were, respectively, 78 and 30\% for dyes and alizarin red. Following the third calcination, the HA/dye ratios decreased to 2 . The loss of reagent as a function of trial numbers is illustrated in Fig. 5. The color abatement diminished progressively after each trial as the ratio $r_{\mathrm{m}}$ of $\mathrm{HA}$ to dye weight decreased (Fig. 6). Two types of dyes can be determined: those that react very well with HA (with abatement rates above $75 \%$ no matter the $r_{\mathrm{m}}$ ratio) and those that react only partially with HA (with abatement rates near $20 \%$ even with large $r_{\mathrm{m}}$ ratios).

It can be seen that the dye adsorption capacities are good for most dyes (between 70 and 99\% elimination) except for $\mathrm{CB}$ which is only slightly eliminated

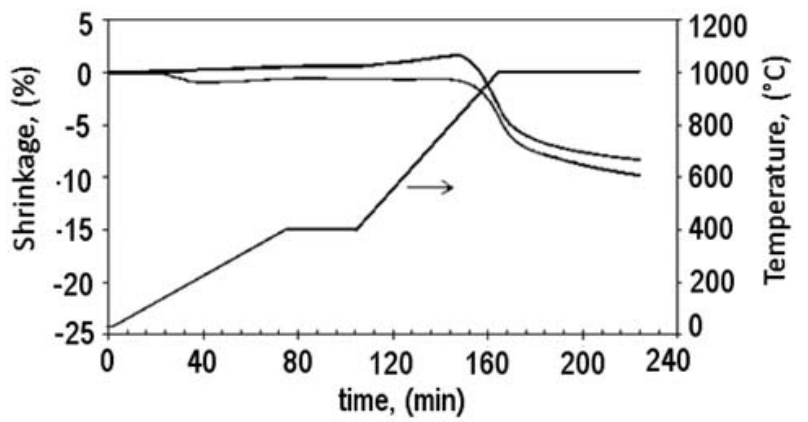

Fig. 2. TMA of calcined HA (top curve) and freshly precipitated HA (lower curve). The temperature program had a $30 \mathrm{~min}$ isothermal period at $400^{\circ} \mathrm{C}$. 


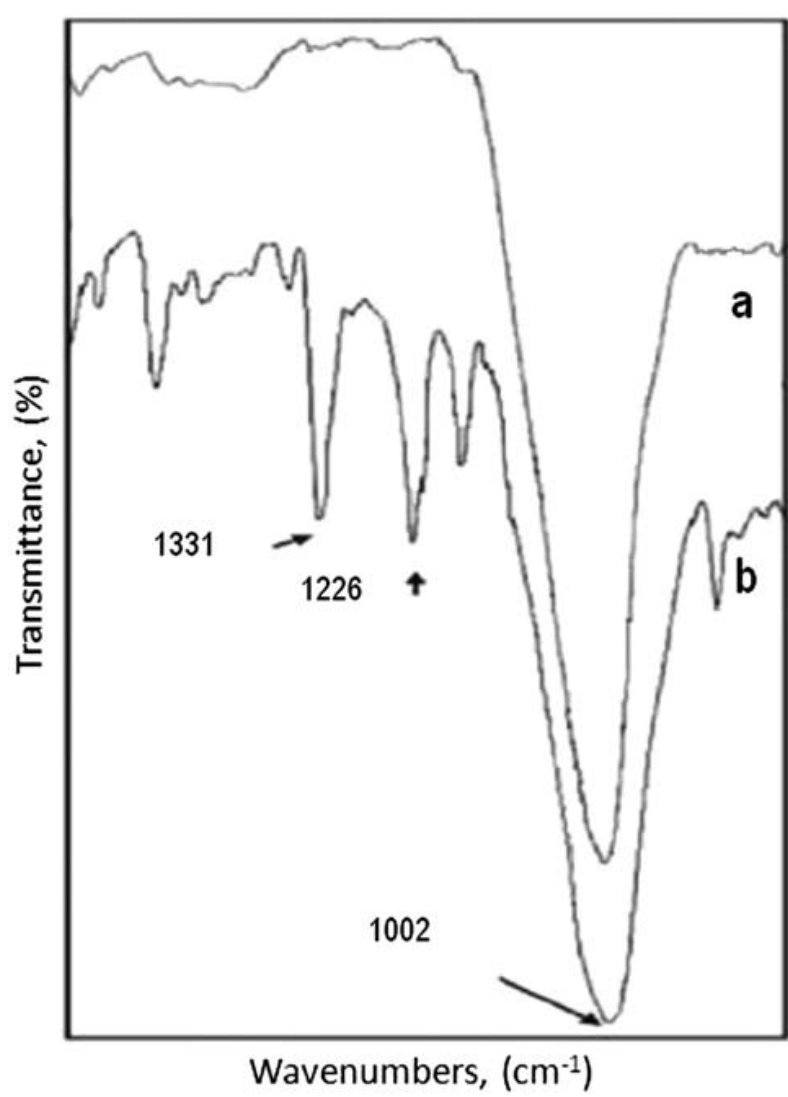

Fig. 3. Infrared spectra of precipitated calcium phosphate (a) and co-precipitated calcium phosphate with Dianix red dye (b).

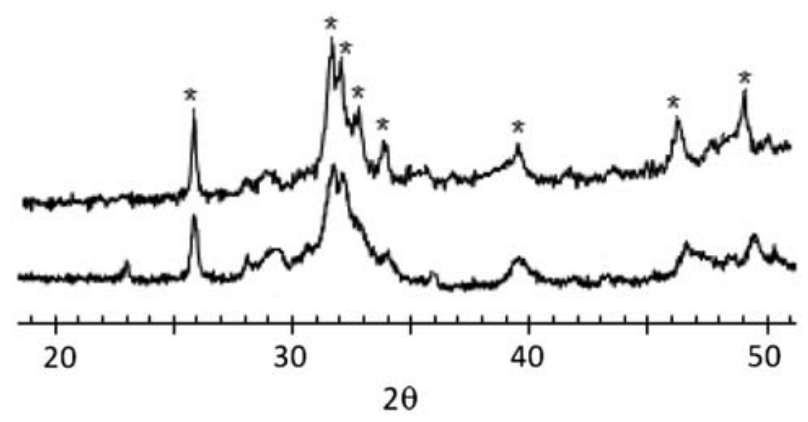

Fig. 4. XRD patterns observed for freshly precipitated HA (lower pattern) and recycled (calcined) HA with the stars indicating typical HA peaks.

from solution (from 18 to $7 \%$ ). The removal capacities remain similar for most dyes, except for the copper containing ST dye where the abatement drops from $94 \%$ in the first step to $75 \%$ on the fourth reuse. This can be related to the fact that copper is not eliminated by the thermal treatment and remains in the HA solids thereby modifying the reagent properties. It is

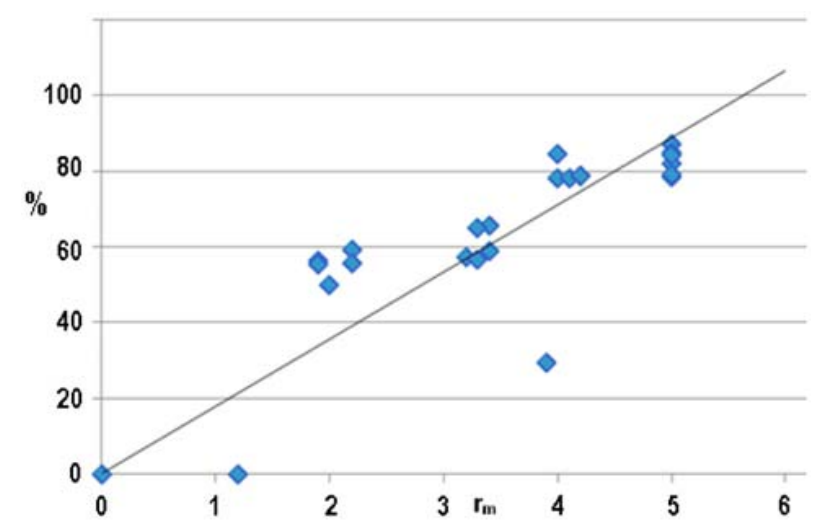

Fig. 5. \% HA recovered as a function of the ratio $r_{\mathrm{m}} \mathrm{mg}$ $\mathrm{HA} / \mathrm{mg}$ Dye.

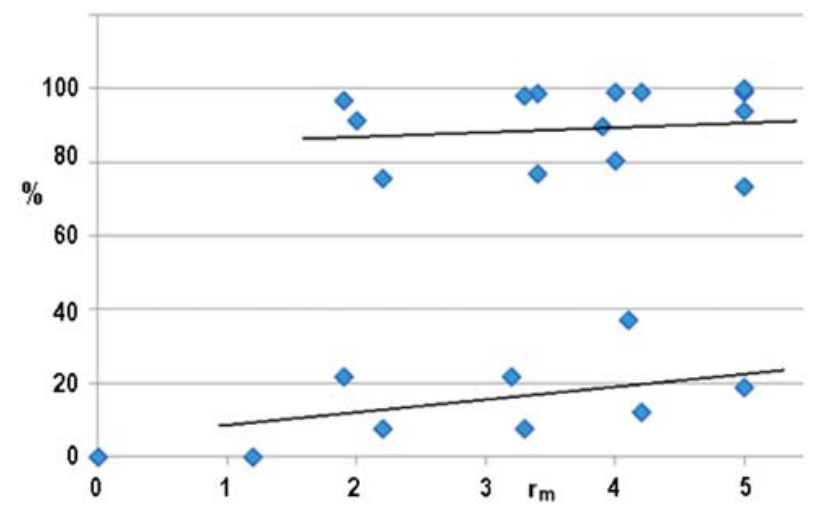

Fig. 6. \% Dye removed as a function of the ratio $r_{\mathrm{m}} \mathrm{mg}$ $\mathrm{HA} / \mathrm{mg}$ Dye.

notable that even with low reagent/dye ratios below 2 , the dye removal is performing well (97\% elimination for DR dye and 99\% elimination for HB dye).

The losses in recovered HA can be attributed to two factors which are experimental physical loses during filtration, drying, and thermal treatment steps, and solubility losses caused by incomplete precipitation due to limited but small solubility of HA, particularly in the presence of dyes which tend to slow the HA precipitation process. This is why the losses became more important when smaller amounts of HA were available. Clearly, the HA loss increased as the amount of reagent diminished. This is why we tried using large excess HA quantities to eliminate small amounts of dyes, which were recovered following filtration and calcination.

To gain more insight into the influence of the reagent/dye ratio effects, further experiments were carried out with predetermined $r_{\mathrm{m}}$ ratios at longer time periods $(6 \mathrm{~h})$ to allow for more complete precipitation. Results showed that nearly complete dye removal could be achieved by standing $6 \mathrm{~h}$ for 
complete co-precipitation and that color abatement increased when more reagents were used. Correspondingly, the amount of solids lost decreased when more was used. The best results were obtained when the weight of HA reagent was 5 times the amount of dye weight present in solution. This represents $2.5 \mathrm{~g}$ of reagent per liter of water to be treated, but with more than $2 \mathrm{~g}$ recovered, the spent reagent only represents $0.5 \mathrm{~g}$ per liter. From these results, it can be appreciated that HA works well for most cases except for the CB (Cibacron Blue) dye.

The fact that some HA is lost due to dissolution in water should be uneventful in the environment for lack of toxicity of calcium and small amounts of phosphate. The strong adsorption of some dyes on the HA precipitates can be explained by strong interaction between phenolic groups in the organic molecules and the calcium ions. This is particularly well illustrated by the case of Alizarin AR, a known histological stain for calcified tissues. When small $r_{\mathrm{m}}$ ratios are used, it is not the calcium phosphate which precipitates out of solution but the calcium-alizarin complex, which results in little calcium phosphate recovery following thermal treatment, unless larger $r_{\mathrm{m}}$ ratios are used. Among the dyes considered, Red disperse 167 (DR) and Hydron Blue (HB) were strongly removed. Five successive experiments were run with a large and constant HA/dye mass ratio of 20 using the recovered HA in each consecutive test, following regeneration. After each run, the elimination yield was close to $97 \%$ for DR and $99 \%$ for HB. In addition, about 85 and $86 \%$ of calcined apatite was recovered for RD and $\mathrm{HB}$, respectively; therefore, the HA mass loss deduced was, respectively, 15 and 14\%. After standing overnight, the solution became nearly colorless (elimination yield $E=99.9 \%$ ) and a gel residue formed in the bottom of the vessel.

\section{Conclusion}

Wastewaters contaminated by mixed textile dyes can be treated to eliminate dilute dyes by a precipitation reaction formed near neutral $\mathrm{pH}$ in the presence of calcium and phosphate ions. Following sedimentation or filtration, the co-precipitated dyes and calcium phosphates can be thermally treated to mineralize the organic molecules and regenerate the calcium phosphates for further reuse. This makes the treatment process durable and lean in chemical consumptions. Calcium and phosphate salts are inexpensive, and with proper thermal combustion, no other pollution results from the water purification process. This should be an incentive for economically and environmentally concerned operators. In fact, with such a method, the water is purified; the solids can be calcined and the ashes regenerated into new reagent and valorized again, with no final waste to dispose of.

\section{Acknowledgment}

We thank the Algerian Ministry of Education for a study and travel grant.

\section{References}

[1] E. El Ouardi, M.I. Mrani, M. Anoua, H. Chehouani, Optimisation du traitement thermique d'un phosphate application au phosphate du bassin Gantour au Maroc [Optimization of a thermal treatment for a phosphate from the Gantour quary in Marocco], Matériaux Techniques 97 (2009) 133-142.

[2] V.K. Gupta, R. Jain, S. Varshney, Removal of Reactofix golden yellow 3 RFN from aqueous solution using wheat husk-An agricultural waste, J. Hazard. Mater. 142 (2007) 443-448.

[3] A. Andrzejewska, A. Krysztafkiewicz, T. Jesionowski, Treatment of textile dye wastewater using modified silica, Dyes Pigm. 75 (2007) 116-124.

[4] B.Y. Gao, Yue Qin-Yan, Y. Wang, W.Z. Zhou, Color removal from dye-containing wastewater by magnesium chloride, J. Environ. Manage. 82 (2007) 167-172.

[5] Z.J. Hu, Y. Xiao, D.H. Zhao, Y.L. Shen, H.W. Gao, Preparation of dye waste-barium sulfate hybrid adsorbent and application in organic wastewater treatment, J. Hazard. Mater. 175 (2010) 179-186.

[6] V.K. Gupta, A. Mittal, A. Malviya, J. Mittal, Process development for removal and recovery of metanil yellow by adsorption on waste materials-Bottom ash and de-oiled soya, J. Hazard. Mater. 151 (2008) 834-845.

[7] V.K. Gupta, D. Mohan, S. Sharma, M. Sharma, Application of low cost adsorbents for dye removal-A review, J. Environ. Manage. 90(8) (2009) 2313-2342.

[8] M.H. Isa, L. Siew Lang, A.H. Faridahect, Low cost removal of disperse dyes from aqueous solution using palm ash, Dyes Pigm. 74 (2007) 446-453.

[9] S. Wang, H. Wu, Environmental-benign utilisation of fly ash as low-cost adsorbents, J. Hazard. Mater. 136 (2006) 482-501.

[10] M. Pratap Reddy, A. Venugopal, M. Subrahmanyam, Hydroxyapatite photocatalytic degradation of calmagite (an azo dye) in aqueous suspension, Appl. Catal. B 69 (2007) 164-170.

[11] N. Barka, S. Qourzal, A. Assabbane, A. Nounah, Y. Aît-Ichou, Adsorption of Disperse Blue SBL dye by synthesized poorly crystalline hydroxylapatite, J. Environ. Sci. 20(10) (2008) 1268-1272.

[12] A. Nzihou, P. Sharrock, Role of phosphate in the remediation and reuse of heavy metal polluted wastes and sites, Waste Biomass Valorizat. 1 (2010) 163-174.

[13] S.J. Allen, B. Koumanova, Decolourisation of water/wastewater using adsorption (review), J. Univ. Chem. Technol. Metall. 40(3) (2005) 175-192.

[14] H. El Boujady, A. El Rhilassi, M. Bennani-Ziatni, R. El Hamri, A. Taitai, J.L. Lacout, Removal of a textile dye by adsorption on synthetic calcium phosphates, Desalination 275(1-3) (2011) 10-16.

[15] N. Barka, A. Assabbane, A. Nounah, L. Laanab, Y. Aît Ichoua, Removal of textile dyes from aqueous solutions by natural phosphate as a new adsorbent, Desalination 235 (2009) 264-275.

[16] B. Acemioglu, Adsorption of Congo Red from aqueous solution onto calcium-rich fly ash, J. Colloid Interface Sci. 274 (2004) 371-379.

[17] K. Klemola, U. Honkalampi-Hamalainen, J. Liesivuori, J. Pearson and P. Lindstrom-Seppa, Evaluating the toxicity of reactive dyes and fabrics with the spermatozoa motility inhibition test, AUTEX Res. J. 6 (2006) 182-190. 